\title{
ALTERNATIVAS PARA A MOBILIDADE URBANA
}

\author{
OS CIDADÃOS DESEJAM RECONQUISTAR OS LOCAIS \\ PÚBLICOS DE CONVIVÊNCIA, OS QUAIS FORAM \\ TOMADOS POR UM URBANISMO PERVERSO QUE \\ VALORIZA O INDIVIDUAL. OS SISTEMAS INTEGRADOS \\ DE TRANSPORTE PÚBLICO APARECEM COMO UMA \\ POSSIBILIDADE FAVORÁVEL NO ATUAL CENÁRIO
}

\author{
| POR ALEXANDRE DELIJAICOV
}

\section{O PROBLEMA DA MOBILIDADE NAS CIDADES}

A sensação de bem-estar nas cidades depende, muitas vezes, da qualidade das estruturas ambientais urbanas. Rios, ferrovias, ruas e avenidas são eixos que podem contribuir para a construção de um cenário que aproxima as pessoas, promovendo o encontro, a convivência e a confiança no outro.

Esquinas e largos culturais de confluência de pessoas e passeios públicos reforçam o conceito de "rua viva" e "urbanismo lento". As praças equivalem a salas de estar sem teto na escala da comunidade. A arquitetura primordial é a construção coletiva do local, ou seja, trata-se da constituição e conquista coletiva dos lugares públicos da cidade, a invenção mais importante da humanidade: uma obra de arte aberta, inconclusa (no bom sentido), passível de ser modificada e transformada. É o lugar onde nos inventamos.

No entanto, o problema dos espaços urbanos não está nas infraestruturas físicas e territoriais de saneamento ambiental, mobilidade urbana e transporte público, mas sim na mentalidade das pessoas. Hoje, as cidades não passam de acampamentos improvisados, reféns de um "urbanismo perverso", mercantilista, em uma sociedade de consumo inconsequente, egoísta e abduzida pelo capital selvagem oriundo de nosso passado colonial. Mas podemos imaginar que tudo pode ser diferente se conseguirmos fazer a reforma urbana (e agrária) necessária para evitar o desastre cotidiano e construir um lugar com qualidade ambiental para todos.

\section{O TRANSPORTE PÚBLICO}

A liberdade de ir e vir com dignidade pela cidade, seja caminhando, pedalando ou por meio do transporte público - de preferência sobre trilhos - é um dos fatores que contribuem para a sensação de bem-estar individual e coletiva. A qualidade das infraestruturas ambientais nos espaços urbanos deve estar na prioridade dos investimentos em locais de passeios 



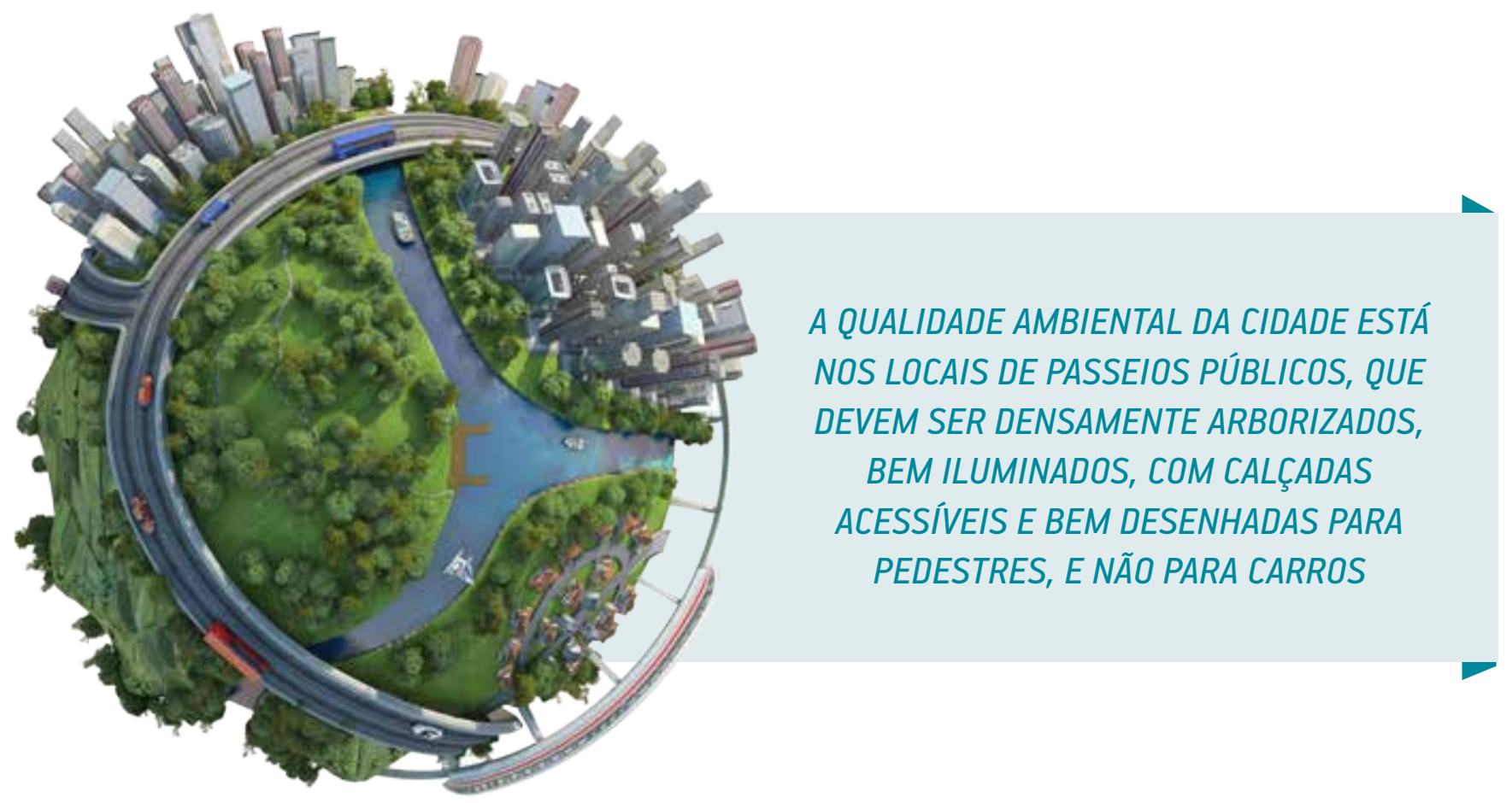

públicos, que precisam ser densamente arborizados, bem iluminados, com calçadas acessíveis e bem desenhadas para pedestres.

Essa infraestrutura leve e capilar contribui para a livre circulação de pedestres e ciclistas de forma digna e segura, no trajeto para a escola, o trabalho etc. A prioridade para calçadas e ciclofaixas revela um urbanismo humanista, social, público e coletivo, em oposição ao urbanismo mercantilista e rodoviarista, no qual a cidade é vista como mercadoria, acreditando-se que ela pertença ao automóvel particular.

O conceito latente dos 20 minutos casa-escola/casa-trabalho, a pé, de bicicleta ou de transporte público, representa a antítese do espaço urbano que mantém o cotidiano centro-periferia massacrante para a maioria dos cidadãos. A urgente reforma urbana tão desejada é a da cidade com várias centralidades, com oportunidade de moradia e emprego para todos, com praças de equipamentos sociais - verdadeiros centros de estruturação urbana - que promovem o encontro, a convivência e a diversidade, visando à construção coletiva da qualidade do lugar.

\section{TRANSPORTES ALTERNATIVOS COMO MEIOS DE LOCOMOÇÃO}

Os sistemas integrados de transportes públicos de passageiros e cargas devem considerar a interligação multimodal hidroviária, ferroviária, rodoviária, cicloviária e aeroviária, além de elevadores públicos, planos inclinados e teleféricos em cidades que precisam superar problemas de transposições de desníveis ou vales, como a transposição cidade-baixa/cidade-alta.

A bicicleta é uma das invenções mais extraordinárias da humanidade. É um veículo urbano. Sabemos que é o meio de transporte mais rápido para percursos de até $5 \mathrm{~km}$ na cidade. Regiões com ladeiras trazem uma vantagem para o ciclista: ele não faz esforço durante metade do percurso, pois não precisa tracionar o pedal constantemente, como em cidades totalmente planas.

Evidentemente, a multimodalidade considera a integração com os demais transportes públicos. Por isso, é fundamental a implantação de bicicletários nas estações de trem, metrô e em terminais de ônibus. Um exemplo notável é o bicicletário de Mauá, na região metropolitana de São Paulo, que foi criado a partir de uma iniciativa privada e opera em um espaço cedido pela Companhia Paulista de Trens Metropolitanos (CPTM) ao lado da estação de trem da cidade. Com capacidade para 2 mil bicicletas, é o maior da América Latina e possui oficina, brechó de peças usadas, além de fazer empréstimos de bicicletas aos usuários.

Porém, para construirmos uma nova cultura de mobilidade urbana - com ênfase no pedestre e no ciclista - , políticas, programas e ações precisam priorizar a educação e a cultura cicloviária em escolas e demais equipamentos públicos, os quais deveriam disponibilizar bicicletários, assim como os estabelecimentos comerciais e de serviço também precisam de incentivos para a sua implantação. 


\section{CAMINHOS PARA UMA MOBILIDADE MAIS EFICIENTE}

Uma possível alternativa para melhorar a mobilidade nas cidades seria priorizar o transporte público, reconstruir a rede de ferrovias e ativar as hidrovias regionais e nacionais. Melhorar a mobilidade depende também de um projeto de reforma urbana e agrária que reestruture o território nacional, com uma rede de cidades brasileiras mais equilibradas, interligadas pela multimodalidade hidroviária, ferroviária, rodoviária, cicloviária e aeroviária, ou seja, uma mobilidade, de fato, mais democrática e pública.

O caminho possivelmente mais inteligente, mas difícil de ser absorvido pelos usuários de automóveis particulares,

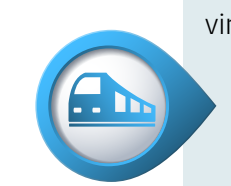

\section{BONDES, BICICLETAS E BARCOS}

Esses meios são possíveis caminhos para melhorar a mobilidade nas cidades. Os três "Bs" - mais do que bons, bonitos e baratos - são amigáveis com a escala humana, contribuem para a qualidade do ambiente e valorizam a dignidade do ir e vir dos cidadãos.

\section{TRILHOS}

Sistemas interligados de trilhos de baixa, média e alta capacidade para levar passageiros, ou seja, bondes, trens e metrôs, respectivamente, constituem os transportes fundamentais para as cidades. A partir deles, os demais meios sobre pneus complementam a capilaridade necessária ao transporte público. A inclusão de corredores de ônibus, por exemplo, pode contribuir, no curto prazo, para a melhoria da mobilidade urbana, principalmente se os novos ônibus elétricos com piso baixo forem utilizados.

Entretanto, a implantação de uma rede de bondes elétricos (integrada às estações de metrô e de trem), com piso baixo, ar condicionado, confortáveis e acessíveis, com velocidade amigável e interligado com o passeio público, é, sem dúvida, o mais adequado para a melhoria da mobilidade e da qualidade ambiental urbana.

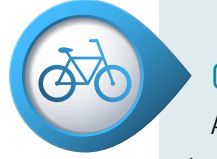

\section{CICLOVIAS}

A implantação das infraestruturas cicloviárias nas cidades é o caminho mais inteligente, barato e rápido para mudar a mentalidade existente, já que pode ser articulada com políticas educacionais e culturais, visando à reforma urbana que valoriza conceitos de "rua viva" (para o encontro das pessoas), "urbanismo lento" (do caminhar e pedalar), "esquinas culturais" (de encontro, convivência e confiança) e "infraestrutura leve e é transformar todas as vias expressas em avenidas com semáforos a cada cem metros - possibilitando a travessia de pedestres - com largos passeios públicos e densamente arborizados. As marginais dos rios urbanos, por exemplo, tornariam-se espaços com calçadões e um parque fluvial linear.

Priorizando o transporte coletivo, bem como os veículos urbanos não motorizados e, principalmente, os pedestres, as vias expressas seriam transformadas em bulevares fluviais com velocidade máxima permitida de $40 \mathrm{~km} / \mathrm{h}$, onde os veículos seriam orquestrados pelo sistema de semáforos e pedágios urbanos e o trânsito seria menos congestionado.

capilar" (de largos passeios públicos, acessíveis, arborizados, iluminados e com calçada para organização racional das demais estruturas subterrâneas que constituem as ruas).

\section{HIDROVIAS}

Sistemas de hidrovias urbanas, constituídos por canais e lagos navegáveis e integrados aos demais meios, também são importantes caminhos para a melhoria da mobilidade urbana, principalmente para o transporte fluvial urbano de cargas públicas, tais como sedimentos de dragagem dos lagos e represas, lodos das estações de tratamento de esgoto e água, lixo urbano, entulho e terra de escavações. O transporte fluvial dessas cargas reduziria significativamente a circulação nas ruas e avenidas de regiões que poderiam implementar esse modelo.

As hidrovias também são adequadas à constituição de ecoportos, que promovem a cultura da reciclagem, da agricultura urbana e a recuperação do cinturão hortifrutigranjeiro. Eles podem ser centros de educação ambiental, que valorizam os rios da região, com feiras de trocas e de hortifrúti.

O transporte fluvial urbano de passageiros pode ser um caminho alternativo, desde que possa ser interligado aos demais meios de transportes públicos. As travessias de lagos e represas com integração tarifária com corredores de ônibus, trens e metrô diminuem percursos de contorno desses corpos d'água.

Mais do que um projeto de transporte, as hidrovias urbanas são eixos de desenvolvimento da orla fluvial e lacustre das cidades, com possibilidade de recuperar a dignidade dos rios e promover a estruturação dos espaços urbanos, com sistemas integrados de parques e portos, praias e cais, e caminhos de convivências que promovam a valorização da natureza nas cidades, que nós inventamos e continuaremos a reinventar. 